\title{
Heat shock protein 27 is over-expressed in tumor tissues and increased in sera of patients with gastric adenocarcinoma
}

\author{
Qiaojia Huang ${ }^{1, a}$, Jianxin Ye ${ }^{3, a}$, Qingling Huang', \\ Wannan Chen ${ }^{2}$, Lin Wang ${ }^{1}$, Wansong Lin ${ }^{1}$, Jianyin \\ $\operatorname{Lin}^{1}$ and $\mathrm{Xu} \operatorname{Lin}^{1,2, *}$ \\ ${ }^{1}$ Key Laboratory of Infection and Oncology, Research \\ Center of Molecular Medicine, Fujian Medical University, \\ Fuzhou, P.R. China \\ ${ }^{2}$ Key Laboratory of Tumor Microbiology, Fujian Medical \\ University, Fuzhou, P.R. China \\ ${ }^{3}$ Department of Surgery, The First Affiliated Hospital of \\ Fujian Medical University, Fuzhou, P.R. China
}

\begin{abstract}
Background: In a previous study, we found that heat shock protein 27 (HSP27) was over-expressed in gastric adenocarcinoma (GA) tissue. In this study, our goal was to further verify the expression profile of HSP27 in patients with GA. Methods: Western blot and immunohistochemistry were employed to determine HSP27 expression in 50 paired tumor and adjacent normal tissue. ELISA was used to quantify serum HSP27 concentrations in the same 50 GA patients and 50 healthy individuals.

Results: Compared to adjacent normal tissues, HSP27 was over-expressed in $25(50 \%, \mathrm{p}=0.000)$ and $24(48 \%, \mathrm{p}=$ 0.000 ) cases of GA tissue by Western blot and immunohistochemistry, respectively. ELISA revealed significantly higher serum concentrations of HSP27 in patients with GA patients (mean $=986 \mathrm{pg} / \mathrm{mL}$ ) compared to healthy individuals $($ mean $=573 \mathrm{pg} / \mathrm{mL})(\mathrm{p}=0.003)$. In addition, infection with Helicobacter pylori (HP) in healthy individuals was associated with increased expression of HSP27 in both gastric mucosa and serum.

Conclusions: These data suggest that HSP27 is overexpressed in GA tissue and serum concentrations of HSP27 are increased in patients with GA. Over-expression of HSP27 may indicate a gastric malignant/infectious process. The detection of serum HSP27 concentrations by ELISA may be useful for screening for GA.

Clin Chem Lab Med 2010;48:263-9.
\end{abstract}

Keywords: ELISA; gastric adenocarcinomas; heat shock protein 27; immunohistochemistry; Western blot.

\footnotetext{
${ }^{a}$ Qiaojia Huang and Jianxin Ye contributed equally to this paper. *Corresponding author: Xu Lin, Key Laboratory of Infection and Oncology, Research Center of Molecular Medicine, Fujian Medical University, 88 Jiaotong Road, Fuzhou 350004, P.R. China Phone: +86-591-83569986, Fax: +86-591-83569132, E-mail: linxu@mail.fjmu.edu.cn

Received August 6, 2009; accepted October 12, 2009;

previously published online December 7, 2009
}

\section{Introduction}

Heat shock protein 27 (HSP27) is a member of the small molecular weight HSP family and is a major molecular chaperone with a role in regulating normal cell physiology and the cellular stress response (1-3). HSP27 prevents protein aggregation, helps in the correct folding of proteins, and assists with the formation of multi-protein complexes, and recovers the protein structure for proteins that denature during cell stress $(4,5)$. Besides these main chaperone functions, HSP27 has been associated with apoptosis and cell proliferation and differentiation (6, 7). Additionally, HSP27 is over-expressed in many kinds of cancers, although its role in cancer remains unclear (8-10).

Gastric cancer is a common and serious malignancy. More than 870,000 new cases are diagnosed worldwide each year, and it has the second highest death rate among all cancers. Previously, we analyzed protein expression patterns in paired gastric adenocarcinoma (GA) and non-neoplastic mucosa tissues using two-dimensional polyacrylamide gel electrophoresis (2D-PAGE) and matrix-assisted laser desorption ionization-time of flight mass spectrometry (MALDI-TOF/ TOF MS) (11). This analysis identified 42 proteins differentially expressed two-fold or greater between tumor and adjacent normal tissues. HSP27 was one of the proteins shown to be over-expressed in GA tissue (11). The present study was performed to further verify its expression profile in patients with GA. To accomplish this objective, expression of HSP27 in GA and matched adjacent normal tissue were detected by Western blot and immunohistochemistry. Also, we measured the concentration of HSP27 in sera of patients with GA and healthy individuals using ELISA.

\section{Materials and methods}

\section{Tissue samples and serum samples}

Fifty GA and matched normal gastric mucosa tissue samples were obtained. Diagnosis of GA was confirmed by analysis of tissue (Table 1), and matched normal gastric mucosa tissue samples were a minimum of $10 \mathrm{~cm}$ from the edge of the cancer tissue. The samples were obtained from fresh surgical material of GA patients from Dongfang Hospital (Fuzhou, Fujian, P.R. China) within 30 min of resection. The samples were stored immediately at $-80^{\circ} \mathrm{C}$ until analysis. In addition, regular paraffin embedded blocks were prepared. For ELISA, we collected serum samples from the 50 patients with GA prior to surgery. We also collected 50 serum samples from healthy individuals at Dongfang Hospital. The age range of the patients with GA was $30-87$ years (median 59 years), and the age range for healthy individuals was $28-76$ years (median 57 years). 
Table 1 HSP27 expression in tumor tissues and sera from patients with gastric adenocarcinomas.

\begin{tabular}{|c|c|c|c|c|c|c|c|c|c|}
\hline \multirow[t]{2}{*}{$\begin{array}{l}\text { Patient } \\
\text { number }\end{array}$} & \multirow[t]{2}{*}{ Sex } & \multirow[t]{2}{*}{$\begin{array}{l}\text { Age, } \\
\text { years }\end{array}$} & \multicolumn{2}{|c|}{$\begin{array}{l}\text { HSP } 27 \text { expression } \\
\text { detection }\end{array}$} & \multirow{2}{*}{$\begin{array}{l}\text { Pathological } \\
\text { changes of the paired } \\
\text { non-neoplastic mucosa }\end{array}$} & \multirow{2}{*}{$\begin{array}{l}\text { HSP27 } \\
\text { serum level, } \\
\mathrm{pg} / \mathrm{mL}\end{array}$} & \multirow[t]{2}{*}{$\begin{array}{l}\text { Histological } \\
\text { type }\end{array}$} & \multirow[t]{2}{*}{$\begin{array}{l}\text { Differentiation } \\
\text { grade }\end{array}$} & \multirow[t]{2}{*}{$\begin{array}{l}\text { TNM } \\
\text { stage }\end{array}$} \\
\hline & & & $\begin{array}{l}\text { Western } \\
\text { blot }^{\mathrm{a}}\end{array}$ & $\mathrm{IHC}^{\mathrm{b}}$ & & & & & \\
\hline 1 & $\mathrm{~F}$ & 64 & +1.6 & +2.4 & Mild AtroG & 1866 & Intestinal & High & T2N0MX \\
\hline 2 & M & 75 & 1.0 & 1.0 & Severe ActiG & 881 & Intestinal & Poor & T3N2MX \\
\hline 3 & M & 55 & ND & ND & Unchanged & 56 & Intestinal & Moderate & T4N2MX \\
\hline 4 & M & 58 & +4.6 & +3.9 & Unchanged & 1072 & Intestinal & Poor & T2NOMX \\
\hline 5 & M & 58 & +2.1 & +5.7 & Unchanged & 1025 & Diffuse & Signet-ring & T3N1MX \\
\hline 6 & M & 61 & 1.0 & 1.0 & Severe ActiG & 1307 & Intestinal & Poor & T2N1MX \\
\hline 7 & M & 32 & +2.5 & +3.6 & Unchanged & 1133 & Intestinal & Moderate & T2N0MX \\
\hline 8 & M & 48 & +9.0 & +8.3 & Unchanged & 991 & Intestinal & Moderate & T1N0MX \\
\hline 9 & $\mathrm{~F}$ & 47 & -0.8 & -0.6 & Severe IM & 370 & Intestinal & High & T2N0MX \\
\hline 10 & $\mathrm{~F}$ & 53 & 1.0 & 1.0 & $\begin{array}{l}\text { Moderate AtroG } \\
\text { with mild ActiG }\end{array}$ & 328 & Diffuse & Signet-ring & T2N1MX \\
\hline 11 & M & 49 & +3.6 & +7.2 & Unchanged & 2500 & Diffuse & Mucinous & T4N2Mx \\
\hline 12 & $\mathrm{~F}$ & 71 & ND & 1.0 & Severe AtroG & 75 & Intestinal & Poor & T2N1MX \\
\hline 13 & M & 51 & -0.6 & -0.7 & Severe ActiG & 400 & Intestinal & Moderate & T1N0MX \\
\hline 14 & $\mathrm{~F}$ & 72 & +4.1 & +1.7 & Mild AtroG & 1131 & Intestinal & Moderate & T2N0Mx \\
\hline 15 & $\mathrm{~F}$ & 58 & 1.0 & 1.0 & Severe ActiG & 725 & Intestinal & Moderate & $\mathrm{T} 2 \mathrm{~N} 1 \mathrm{Mx}$ \\
\hline 16 & M & 59 & +7.2 & +11.6 & Unchanged & 2500 & Intestinal & Poor & T4N1Mx \\
\hline 17 & M & 87 & +5.4 & +4.1 & Unchanged & 1902 & Intestinal & Moderate & T3N1Mx \\
\hline 18 & $\mathrm{~F}$ & 48 & +3.2 & 1.0 & Severe ActiG & 980 & Intestinal & Poor & T3N1Mx \\
\hline 19 & M & 54 & 1.0 & 1.0 & Moderate ActiG & 426 & Intestinal & Moderate & T3N2Mx \\
\hline 20 & M & 74 & +1.4 & +1.7 & Mild AtroG & 1083 & Intestinal & Moderate & T1N0Mx \\
\hline 21 & M & 48 & -0.7 & -0.8 & Moderate IM & 218 & Intestinal & Poor & T2N0Mx \\
\hline 22 & M & 47 & +8.3 & +8.0 & Unchanged & 2500 & Diffuse & Signet-ring & T3N0Mx \\
\hline 23 & M & 43 & 1.0 & 1.0 & Moderate IM & 568 & Intestinal & Poor & T3N2Mx \\
\hline 24 & M & 46 & ND & 1.0 & Severe AtroG & 67 & Diffuse & Mucinous & T3N0Mx \\
\hline 25 & M & 69 & 1.0 & 1.0 & Moderate IM & 801 & Intestinal & Moderate & $\mathrm{T} 2 \mathrm{~N} 2 \mathrm{Mx}$ \\
\hline 26 & M & 65 & +10.4 & +6.5 & Unchanged & 2500 & Intestinal & Poor & T3N1Mx \\
\hline 27 & $\mathrm{~F}$ & 50 & +1.9 & +1.6 & Mild AtroG & 1018 & Intestinal & Early stage GA & T1N0Mx \\
\hline 28 & M & 72 & +2.5 & +3.4 & Mild AtroG & 1212 & Intestinal & Moderate & T2N0Mx \\
\hline 29 & M & 41 & ND & ND & Unchanged & 51 & Intestinal & High & $\mathrm{T} 2 \mathrm{~N} 1 \mathrm{Mx}$ \\
\hline 30 & $\mathrm{~F}$ & 30 & 1.0 & 1.0 & Severe IM & 512 & Intestinal & Poor & T3N1Mx \\
\hline 31 & M & 69 & +6.6 & +4.3 & Unchanged & 1574 & Intestinal & Poor & T3N0Mx \\
\hline 32 & $\mathrm{~F}$ & 38 & 1.0 & 1.0 & Severe Actig & 846 & Diffuse & Signet-ring & T3N1Mx \\
\hline 33 & M & 51 & +4.9 & +2.9 & Mild AtroG & 2481 & Intestinal & High & T4N2Mx \\
\hline 34 & $\mathrm{~F}$ & 36 & 1.0 & 1.0 & Moderate ActiG & 631 & Intestinal & Poor & T3N0Mx \\
\hline 35 & $\mathrm{~F}$ & 67 & 1.0 & -0.8 & Severe IM & 466 & Intestinal & Early stage GA & T1N0Mx \\
\hline 36 & M & 75 & -0.6 & 1.0 & Moderate ActiG & 307 & Diffuse & Mucinous & T3N1Mx \\
\hline 37 & $\mathrm{~F}$ & 74 & +5.2 & +9.9 & Unchanged & 2301 & Intestinal & Poor & T3N2Mx \\
\hline 38 & $\mathrm{~F}$ & 61 & +3.3 & +7.4 & Unchanged & 2094 & Intestinal & Moderate & T3N1Mx \\
\hline 39 & M & 48 & ND & ND & Unchanged & 177 & Intestinal & Moderate & T1N0Mx \\
\hline 40 & M & 50 & +4.4 & +2.1 & Mild AtroG & 1234 & Intestinal & Poor & T3N1Mx \\
\hline 41 & M & 43 & 1.0 & 1.0 & Moderate ActiG & 258 & Intestinal & Moderate & T2NOMX \\
\hline 42 & $\mathrm{~F}$ & 76 & +2.1 & +1.8 & Mild AtroG & 1005 & Diffuse & Signet-ring & $\mathrm{T} 2 \mathrm{~N} 2 \mathrm{MX}$ \\
\hline 43 & M & 68 & 1.0 & 1.0 & Mild IM & 203 & Intestinal & Moderate & T2N1MX \\
\hline 44 & M & 81 & 1.0 & 1.0 & Mile IM & 341 & Intestinal & Moderate & T3N1MX \\
\hline 45 & M & 74 & +2.9 & +3.0 & Unchanged & 1157 & Intestinal & Poor & T2N1MX \\
\hline 46 & M & 53 & +3.1 & +3.3 & Unchanged & 1348 & Diffuse & Mucinous & T3N2MX \\
\hline 47 & $\mathrm{~F}$ & 75 & 1.0 & 1.0 & Mild IM & 162 & Intestinal & Moderate & T1N0MX \\
\hline 48 & $\mathrm{~F}$ & 69 & +3.6 & +2.4 & Mild AtroG & 1292 & Intestinal & Poor & T3N1MX \\
\hline 49 & $\mathrm{~F}$ & 79 & +1.4 & +1.6 & Mild AtroG & 997 & Intestinal & Moderate & T2N1MX \\
\hline 50 & M & 77 & 1.0 & 1.0 & $\begin{array}{l}\text { Moderate Atrog } \\
\text { with mild Actig }\end{array}$ & 298 & Intestinal & Poor & T2N0MX \\
\hline
\end{tabular}

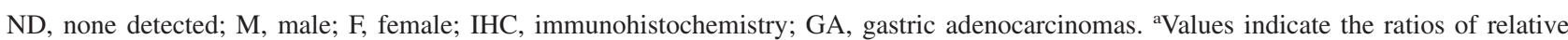
intensity (nomalized to $\beta$-tubulin) measured in GA vs. paired non-neoplastic tissue; " + " indicates over-expression; " - " indicates downexpression, and 1.0 is considered no changes. "Values indicate the ratios of GA vs. paired non-neoplastic tissue; "+" indicates overexpression; "-," indicates down-expression, and 1.0 is considered no changes. ActiG indicates chronic active gastritis; AtroG indicates atrophy gastritis; IM indicates intestinal metaplasia. 


\section{Ethics}

Use of the serum samples, and GA tissue and paired non-neoplastic mucosa tissue for this study was approved by the Dongfang Hospital Ethical Committees.

\section{Western blots for HSP27}

Tissues lysates were prepared according to the method described previously (11). The protein concentrations in the GA and matched normal tissue samples were measured using a BCA Protein Quant Kit (Bio-Rad, Hercules, CA, USA). Equal amounts of protein $(35 \mu \mathrm{g})$ were subjected to sodium dodecyl sulfate polyacrylamide gel electrophoresis (SDS-PAGE) (12\%). The blots were transferred onto PVDF membranes (Amersham Bioscience, Piscataway, NJ, USA) and incubated with goat anti-human HSP27 (Santa Cruz Biotechnology, San Diego, CA, USA) at a dilution of 1:1000. The primary antibodies were detected with horseradish peroxidaseconjugated mouse anti-goat antibodies (Santa Cruz Biotechnology) at a dilution of 1:1000. The immunoreactive protein bands were visualized using enhanced chemiluminscent reagents (Amersham Bioscience). Western blotting of the same sample with anti- $\beta$-tubulin (Santa Cruz Biotechnology) was used as the control. The signal intensity was measured with ImageQuant TL v2003.03 analysis software (Amersham Bioscience). The relative intensity (RI) of HSP27 was normalized to $\beta$-tubulin, and the ratios of RI of GA vs. paired non-neoplastic tissue were calculated.

\section{Immunohistochemistry for human HSP27}

The blocks of paraffin-embedded human GA and matched normal tissue sections were sectioned, placed on glass slides, and baked for $2 \mathrm{~h}$ at $60^{\circ} \mathrm{C}$. Tissues were deparaffinized with three changes of xylene, then with a series of ethanol (100\%, 95\%, 95\% and $80 \%)$, followed by rinsing with distilled water for $5 \mathrm{~min}$. Antigen retrieval was performed by putting the slides into boiling citrate buffer $\left(100^{\circ} \mathrm{C}\right)$ for $90 \mathrm{~s}$, and $3 \% \mathrm{H}_{2} \mathrm{O}_{2}$ was used to quench endogenous peroxidase interference. After washing with phosphate buffered saline (PBS), the slides were covered with preimmune rabbit serum for $10 \mathrm{~min}$ and washed again in PBS. Primary goat anti-human HSP27 antibody (Santa Cruz Biotechnology), at a dilution of 1:200, was added to each sample, followed by incubation for $3 \mathrm{~h}$ at room temperature (RT). After three washes in PBS, the slides were incubated with a biotin-labeled rabbit anti-goat IgG secondary antibody (Santa Cruz Biotechnology) for $10 \mathrm{~min}$ at RT. The slides were washed in PBS again, and incubated with streptavidin-HRP (Santa Cruz Biotechnology) for an additional $10 \mathrm{~min}$ at RT. Finally, the slides were incubated with $0.5 \%$ 3,3'-diaminobenzidine tetrahydrochloride (DAB) in PBS containing $0.03 \%$ hydrogen peroxide for $10 \mathrm{~min}$ and counterstained with hematoxylin for $30 \mathrm{~s}$. The slides were viewed with a microscope and the staining results were quantified using Motic Med 6.0A Material Image Analysis System (Motic, Beijing, China). The grade was expressed using a gray scale value, and the ratios of GA vs. paired non-neoplastic tissue were calculated. Samples incubated with PBS rather instead of the primary antibody were used as the negative control, and paraffinembedded liver sections with known positive immunoreactivity for HSP27 were used as the positive control.

\section{ELISA for human HSP27}

Sera from the same 50 GA patients used for immunohistochemistry and 50 healthy individuals were collected, and the concentration of HSP27 was quantitated by ELISA (R\&D Systems, Minneapolis, $\mathrm{MN}$, USA) according to the manufacturer's instructions. The ELISA plates were measured using the Labsystems microtiter plate reader (Thermo, Waltham, MA, USA) at $450 \mathrm{~nm}$. p-Values were obtained using the Wilcoxon two-sample-test.

\section{ELISA for detection of human anti-Helicobacter pylori (HP) IgG in control group}

Human anti-HP $\operatorname{IgG}$ was detected in sera from the 50 healthy individuals using ELISA (Biocup, Shenzen, Guangdong, China) according to the manufacturer's instructions (12). Briefly, $100 \mu \mathrm{L}$ of serum diluted 1:100 in PBS was added to ELISA plates that were precoated with purified HP antigens. After incubation and washing, peroxidase-conjugated anti-human $\operatorname{IgG}$ diluted 1:5000 was added and the plates were incubated and washed again. The color was developed by adding tetramethylbenzidine (TMB) and the reaction was stopped by the addition of $\mathrm{H}_{2} \mathrm{SO}_{4}$. In the final step, the ELISA plates were measured with the Labsystems microtiter plate reader (Thermo) at $450 \mathrm{~nm}$. Samples with absorbance values greater than the cut-off threshold $(0.21)$ were considered positive.

\section{Results}

\section{The over-expression of HSP27 in GA tissues identified by Western blot}

To verify the expression profile of HSP27 in GA tissue, 50 cases of GA and paired non-neoplastic tissues were examined by Western blot with anti-HSP27. In 25 of the 50 GA cases, HSP27 had increased expression compared to the other tissue $(50 \%$, Table $1, \mathrm{p}=0.000$, Wilcoxon signed-ranks test). Over-expression of HSP27 was not correlated with age ( $>50$ vs. $\leq 50, p=0.667, \chi^{2}$-test), gender (female vs. male, $\mathrm{p}=0.061, \chi^{2}$-test), histological type (intestinal vs. diffuse, $\mathrm{p}=0.654, \chi^{2}$-test $)$, TNM stage $\left(\mathrm{p}=0.763, \chi^{2}\right.$-test $)$, and differentiation grade (high vs. poor, $p=0.512, \chi^{2}$-test).

For the remaining 25 cases, no significant difference in the expression of HSP27 was identified in 16 cases (32\%). No signal was observed from either tissue in five cases $(10 \%)$, and four samples from patients with cancer had weaker expression compared with their paired non-cancerous tissue (8\%, Table 1, Figure 1).

Representative results from eight patients are shown in Figure 1. A reactive band of molecular weight $27 \mathrm{kDa}$ was found in GA tissue from seven of eight cases. HSP27 was over-expressed in samples 1, 4, 5, 7 and 8 of the GA tissue, and the intensities of HSP27 expression between GA and paired non-neoplastic tissues were nearly identical in samples 2 and 6, while no signal was detected in either the GA or non-neoplastic tissue from sample 3 .

\section{Over-expression of HSP27 in GA tissues identified by immunohistochemistry}

To identify the localized expression patterns of HSP27 in cancer tissue, samples were examined by immunohistochemistry with anti-HSP27. To elucidate whether the pathological changes in mucosa affected HSP27 expression, we examined the 50 paired non-neoplastic mucosa for the chronic active gastritis (ActiG) (monocyte infiltration or neutrophil infiltration), gastric atrophy, and intestinal metaplasia (IM). 


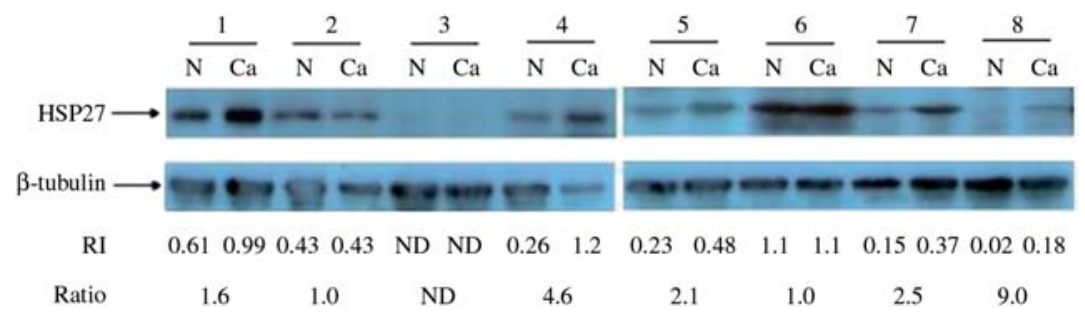

Figure 1 Western blot analysis of HSP27 expression.

Over-expression of HSP27 in GA tissue (Ca) compared to paired non-neoplastic tissue (N) confirmed by Western blotting. Equal amounts of protein from each sample were probed with anti- $\beta$-tubulin as control. The signal intensity measured by ImageQuant TL v2003.03 analysis software, the relative intensity (RI) of HSP27 normalized to $\beta$-tubulin, and the ratios of RI of GA vs. paired non-neoplastic tissue are at the bottom. HSP27 was over-expressed in samples 1, 4, 5, 7 and 8 from tissues with cancer. The intensity of HSP27 expression in cancer and non-cancerous tissues was nearly identical in samples 2 and 6. No signal was detected (ND) in either the cancerous or non-cancerous tissue samples from sample 3 .

The degree of inflammation was graded as normal, mild, moderate, or severe according to the updated Sydney system using visual analog scales applied to microscopic examination results (13). Immunohistochemistry staining revealed that HSP27 was localized to the cytoplasm of cancer tissue (Figure 2C and D) in 24 of the GA samples (24/50, 48\%). In contrast, only weak signals were found in the paired nonneoplastic mucosa (Figure 2A and B). Based on the immunohistochemistry, HSP27 expression was higher in patients with GA compared to the paired normal controls $(p=0.000$, Wilcoxon signed-ranks test). Similar to the results from the Western blots, over-expression of HSP27 was not correlated with increased age ( $>50$ vs. $\leq 50$ years, $p=0.432, \chi^{2}$-test), gender (female vs. male, $\mathrm{p}=0.056, \chi^{2}$-test), histological type (intestinal vs. diffuse, $\mathrm{p}=0.820, \chi^{2}$-test), TNM stage $\left(\mathrm{p}=0.759, \chi^{2}\right.$-test), or differentiation grade (high vs. poor, $\mathrm{p}=0.951, \chi^{2}$-test).

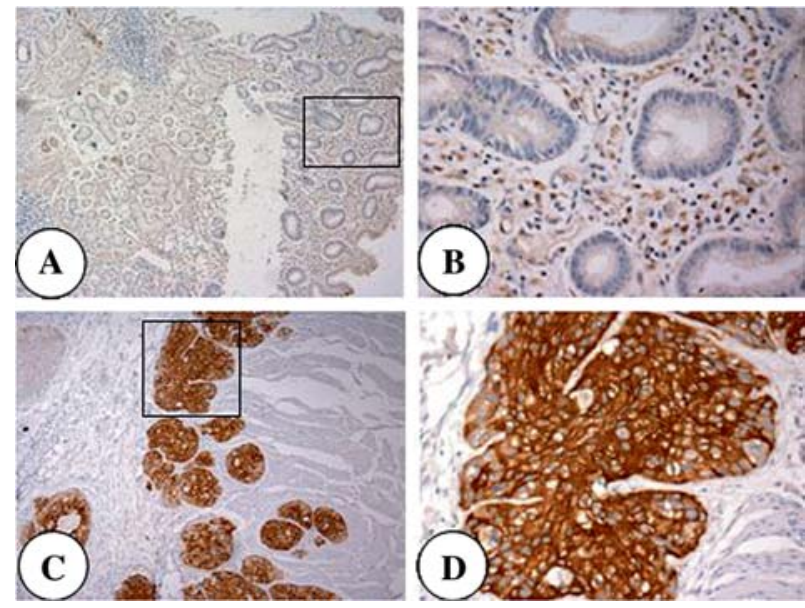

Figure 2 Immunohistochemical analysis of HSP27 expression in gastric adenocarcinoma.

HSP27 was expressed more strongly in the cytoplasm of GA tissue than in the non-neoplastic tissue. The expression of HSP27 in normal stomach $(\mathrm{A}-\mathrm{B})$ and $\mathrm{GA}(\mathrm{C}-\mathrm{D})$. Images on the left panel were made at $\times 100$ magnification; the images on the right were magnified images $(\times 400)$ of the boxed sections depicted at left.
In the immunohistochemistry analysis, no significant difference between cancer and paired non-neoplastic mucosa cells was seen in 19 pairs (38\%). The paired non-neoplastic mucosa in these cases included one, two, and three cases with severe, moderate, and mild IM, respectively, two cases with severe gastric atrophy, two cases with moderate gastric atrophy with mild active gastritis, and five and four cases with severe and moderate active gastritis, respectively. In three $(6 \%)$ other cases, we detected no HSP27 signal from either tissue. Finally, in the remaining four pairs (8\%), the GA samples (cases 9, 13, 21 and 35) had weaker HSP27 signals than their paired non-cancerous tissues. The non-cancerous tissues of three of these four cases had IM (two severe and one moderate). The fourth of these cases had severe active gastritis. In the 24 GA samples with over expression of HSP27, the paired non-neoplastic mucosa had either mild gastric atrophy (10 cases), or were without any significant change (14 cases, Table 1$)$.

The results of histological analysis were consistent with Western blot results showing that HSP27 was over-expressed in the majority of cancer tissues. These results indicate that certain pathological changes in the non-neoplastic mucosa, such as ActiG, gastric atrophy, and IM can show increased HSP27 expression which may mask increased expression by the tumor.

\section{HSP27 concentrations in human serum samples}

To investigate whether there is a link between intracellular and extracellular HSP27 concentrations in gastric neoplasia and to investigate whether HSP27 secreted in patients with GA could be of diagnostic significance, we used ELISA to measure HSP27 concentrations in serum samples from 50 patients with GA and 50 healthy individuals. All 50 GA patients had detectable HSP27 in their serum (Figure 3). The mean serum HSP27 concentrations were 986.40 \pm 742.51 $\mathrm{pg} / \mathrm{mL}$ and $572.54 \pm 506.16 \mathrm{pg} / \mathrm{mL}$ for GA patients and healthy persons, respectively. In most cases, HSP27 concentration was significantly higher in the GA patients $(\mathrm{p}=0.003$, Wilcoxon two-sample test). Our results suggest that a possible screening threshold for GA is $573 \mathrm{pg} / \mathrm{mL}$. In addition, 


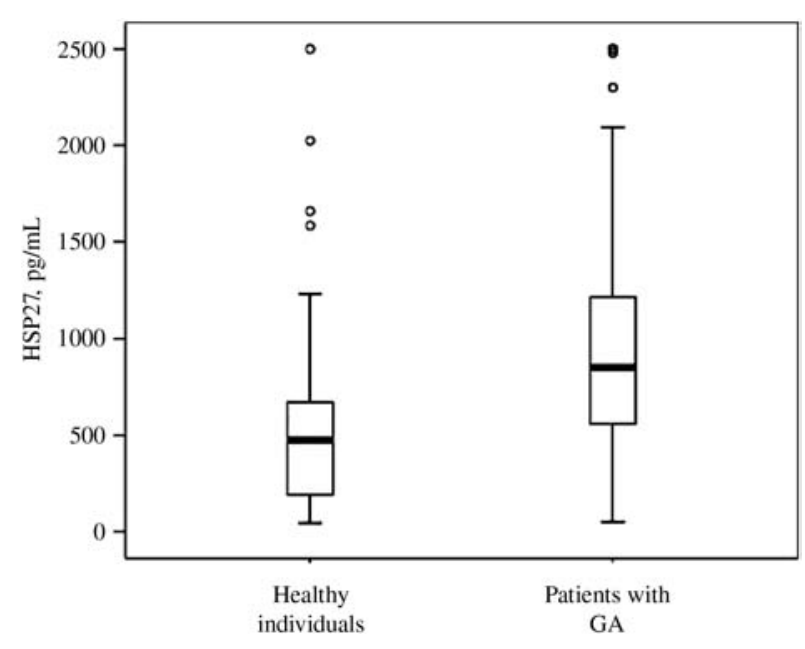

Figure 3 Serum HSP27 concentration by ELISA assay. HSP27 serum concentrations were significantly higher in patients with GA compared to healthy individuals $(\mathrm{p}=0.003)$. The mean concentration of HSP27 was $986 \mathrm{pg} / \mathrm{mL}$ (range 51-2500 pg/mL) for GA patients and $573 \mathrm{pg} / \mathrm{mL}$ (range, $43-2500 \mathrm{pg} / \mathrm{mL}$ ) for healthy individuals. Box plots show serum concentrations of HSP27. The lines inside the boxes are the mean. The box represents the interval between the 25th and 75th percentiles except for data $>1500$ $\mathrm{pg} / \mathrm{mL}$ for healthy individuals and $>2000 \mathrm{pg} / \mathrm{mL}$ for GA patients, which are shown as circles. Seven out of 50 serum samples from patients with GA were $>2000 \mathrm{pg} / \mathrm{mL}$, and 4 out of 50 serum samples from healthy individuals were $>1500 \mathrm{pg} / \mathrm{mL}$.

all GA patients with tissues over-expressing HSP27 had increased serum HSP27 concentrations (shown in Table 1). The HSP27 serum concentrations were correlated positively with HSP27 expression in GA tissues as detected by Western blot and immunohistochemistry.

\section{ELISA for detection of human anti-HP IgG in control group}

Anti-HP IgG seropositivity was detected in 46 of 50 healthy individuals. The results indicated that HP infection may be related with increased HSP27 expression in the serum of controls.

\section{Discussion}

When a cell becomes cancerous, its stress level can increase resulting in changes in $\mathrm{pH}$, cell metabolism, and other cellular events. These changes can disrupt the cell cycle and DNA synthesis, leading to gene mutations and neoplastic progression (14-16). Some cancerous cells over-express HSP27 which may increase cell proliferation and metastasis. Over expression of HSP27 has been reported for a wide variety of tumors, and is associated with poor prognosis of some tumors, including liver and prostate carcinoma (17-24).

The over-expression of HSP27 in gastric cancer has been observed by several studies $(8,25,26)$. In gastric cancer, over-expression of HSP27 may be associated with metastasis to the lymph nodes, advanced stage (III and IV) cancer, and shorter overall survival of patients $(27,28)$, indicating that HSP27 has prognostic significance for gastric cancer. Additionally, HSP27 expression was closely related to gastric tumor size, and the presence of organ metastases (29). However, another study found that HSP27 was not present in metastatic gastric tumors, and was only detectable in samples from non-metastatic gastric cancer tissue (26). None of these studies measured HSP27 serum concentrations to investigate if there is a link between intracellular and extracellular HSP27 concentrations in gastric neoplasia. Previously, we found HSP27 over-expression in 5 of 10 GA tissues using a proteomics technique. Here, we extended that study to more GA patients and investigated the link between intracellular and extracellular HSP27 concentration.

Both Western blotting and immunohistochemistry revealed over-expression of HSP27 in most tumor tissues. Additionally, the concentration of HSP27 in serum samples from patients with GA was significantly higher than that from healthy individuals. Also, serum HSP27 concentrations were positively correlated with HSP27 expression in GA tissue detected by Western blot and immunohistochemistry. Almost all of the patients with HSP27 over-expression in GA tissues also had increased serum HSP27 concentrations.

Although HSP27 expression in cancer tissue and paired non-neoplastic mucosa was nearly identical in case 6 (Figure $1)$, this non-neoplastic mucosa had strong positive expression of HSP27. Infection with HP is also associated with mucosal damage and increased stress production, leading to increased expression of HSP27 $(30,31)$. Using the rapid urease test (RUT) (32), we determined that nine of the non-neoplastic mucosa tissues had HP infection, among these nine samples with HP infection were case 6 and five other cases (cases 9, 13, 21, 35, and 36), in which the paired non-neoplastic mucosa had higher HSP27 expression than the GA tissue. Although HP infection may have resulted in an apparent lack of over-expression in tissue from case $6 \mathrm{GA}$ tissue, the serum concentration of HSP27 (1307 pg/mL) was higher than the mean for patients with GA.

In addition to HP infection, paired non-neoplastic mucosa with ActiG, gastric atrophy, and IM also had increased HSP27 expression, leading to a decreased ratio of HSP27 expression in cancer tissue to normal tissue (Table 1). These pathological changes in non-neoplastic mucosa may mask the increased expression by the tumor and explain why only $50 \%$ of GA tissues had an increase in HSP27 expression. In contrast, these pathological changes were not associated with HSP27 serum concentrations. In almost all cases, HSP27 serum concentrations were closely associated with the overexpression of HSP27 in GA tissue. Future studies should focus on the link between HSP27 serum concentration and over-expression in GA tissue.

HP infection increases HSP27 expression (30, 31). Because 46 of the 50 healthy individuals were infected with $\mathrm{HP}$, the control group might also have had increased HSP expression in their sera due to HP infection. These increased HSP27 concentrations in the control individuals may lead to 
overlapping distributions of HSP27 in serum in GA patients and healthy controls.

HSP27 is constitutively expressed at low levels in the cytosol of most human cells, including cells located in gastric mucosa. These low levels of expression likely indicate an important role for HSP27 in cellular homeostasis and gastric mucosa defense (33-36). In accordance with previous results, we also found HSP27 expressed in majority of gastric mucosa. Although it is accepted that HSP27 is expressed in normal epithelium (37), HSP27-positive healthy individuals may have experienced microbial or viral infection, resulting in stressed mucosa (38). We identified some cases with no HSP27 expression in either the non-neoplastic gastric mucosa or GA tissue. The lack of HSP27 expression was due to limited sensitivity of current methods, individual differences, or other reasons $(37,38)$. These results should be confirmed in future studies.

The data from this study also indicated that over-expression of HSP27 was not related to patient's age, gender, TNM stage, histological type and differentiation grade. Due to the over-expression of HSP27 being found in GA from early through late stages, we thus speculate that HSP27 might be associated with early stage carcinogenesis.

In conclusion, our results demonstrate that HSP27 is overexpressed in GA tissues, and increased in sera from patients with GA. Over-expression of HSP27 may indicate a malignant or infectious process, and the measurement of serum HSP27 concentrations by ELISA may be useful for screening for GA.

\section{Conflict of interest statement}

Authors' conflict of interest disclosure: The authors stated that there are no conflicts of interest regarding the publication of this article. Research funding played no role in the study design; in the collection, analysis, and interpretation of data; in the writing of the report; or in the decision to submit the report for publication.

Research funding: This work was supported by Grants from the Program for Innovation Research Team in Science and Technology in Fujian Province University FMU-RT001, the Project of Science and Technology Development in Fujian Province 2005D087 and Professor Foundation of Fujian Medical University JS07003 (to Xu Lin).

Employment or leadership: None declared.

Honorarium: None declared.

\section{References}

1. Lindquist S, Craig EA. The heat-shock proteins. Annu Rev Genet 1988;22:631-77.

2. Gething MJ, Sambrook J. Protein folding in the cell. Nature 1992;355:33-45.

3. Graner MW, Cumming RI, Bigner DD. The heat shock response and chaperones/heat shock proteins in brain tumors: surface expression, release, and possible immune consequences. J Neurosci 2007;27:11214-27.
4. Wu W, Welsh MJ. Expression of the 25-kDa heat-shock protein (HSP27) correlates with resistance to the toxicity of cadmium chloride, mercuric chloride, cis-platinum(II)-diammine dichloride, or sodium arsenite in mouse embryonic stem cells transfected with sense or antisense HSP27 cDNA. Toxicol Appl Pharmacol 1996;141:330-9.

5. Ferns G, Shams S, Shafi S. Heat shock protein 27: its potential role in vascular disease. Int J Exp Pathol 2006;87:253-74.

6. Garrido C, Brunet M, Didelot C, Zermati Y, Schmitt E, Kroemer G. Heat shock proteins 27 and 70: anti-apoptotic proteins with tumorigenic properties. Cell Cycle 2006;5:2592-601.

7. Vargas-Roig LM, Fanelli MA, Lopez LA, Gago FE, Tello O, Aznar JC, et al. Heat shock proteins and cell proliferation in human breast cancer biopsy samples. Cancer Detect Prev 1997; 21:441-51.

8. Ciocca DR, Calderwood SK. Heat shock proteins in cancer: diagnostic, prognostic, predictive, and treatment implications. Cell Stress Chaperones 2005;10:86-103.

9. Melle C, Ernst G, Escher N, Hartmann D, Schimmel B, Bleul A, et al. Protein profiling of microdissected pancreas carcinoma and identification of HSP27 as a potential serum marker. Clin Chem 2007;53:629-37.

10. Fanelli MA, Montt-Guevara M, Diblasi AM, Gago FE, Tello $\mathrm{O}$, Cuello-Carrión FD, et al. P-Cadherin and beta-catenin are useful prognostic markers in breast cancer patients; beta-catenin interacts with heat shock protein Hsp27. Cell Stress Chaperones 2008;13:207-20.

11. Huang QJ, Huang QL, Chen WN, Wang L, Lin WS, Lin JY, et al. Identification of transgelin as a potential novel biomarker for gastric adenocarcinoma based on proteomics technology. J Cancer Res Clin Oncol 2008;134:1219-27.

12. Long M, Luo J, Li Y, Zeng FY, Li M. Detection and evaluation of antibodies against neutrophil-activating protein of Helicobacter pylori in patients with gastric cancer. World J Gastroenterol 2009; $15: 2381-8$.

13. Kalebi A, Rana F, Mwanda W, Lule G, Hale M. Histopathological profile of gastritis in adult patients seen at a referral hospital in Kenya. World J Gastroenterol 2007;13:4117-21.

14. Edinger AL. Growth factors regulate cell survival by controlling nutrient transporter expression. Biochem Soc Trans 2005; 33:225-7.

15. Griguer CE, Oliva CR, Gillespie GY. Glucose metabolism heterogeneity in human and mouse malignant glioma cell lines. $\mathrm{J}$ Neurooncol 2005;74:123-33.

16. Harguindey S, Orive G, Luis Pedraz J, Paradiso A, Reshkin SJ. The role of pH dynamics and the Na_/H_antiporter in the etiopathogenesis and treatment of cancer. Two faces of the same coin - one single nature. Biochim Biophys Acta 2005; 1756: $1-24$.

17. Downs CA, Jones LR, Heckathorn SA. Evidence for a novel set of small heat-shock proteins that associates with the mitochondria of murine PC12 cells and protects NADH: ubiquinone oxidoreductase from heat and oxidative stress. Arch Biochem Biophys 1999:365:344-50.

18. Dunlop ME, Muggli EE. Small heat shock protein alteration provides a mechanism to reduce mesangial cell contractility in diabetes and oxidative stress. Kidney Int 2000;57:464-75.

19. Rust W, Kingsley K, Petnicki T, Padmanabhan S, Carper SW, Plopper GE. Heat shock protein 27 plays two distinct roles in controlling human breast cancer cell migration on laminin-5. Mol Cell Biol Res Commun 1999;1:196-202.

20. Erkizan O, Kirkali G, Yörükoğlu K, Kirkali Z. Significance of heat shock protein-27 expression in patients with renal cell carcinoma. Urology 2004;64:474-8. 
21. Choi DH, Ha JS, Lee WH, Song JK, Kim GY, Park JH, et al. Heat shock protein 27 is associated with irinotecan resistance in human colorectal cancer cells. FEBS Lett 2007;581:164956.

22. Zanini C, Pulerà F, Carta F, Giribaldi G, Mandili G, Maule MM, et al. Proteomic identification of heat shock protein 27 as a differentiation and prognostic marker in neuroblastoma but not in Ewing's sarcoma. Virchows Arch 2008;452:157-67.

23. Oesterreich S, Weng CN, Qiu M, Hilsenbeck SG, Osborne CK, Fuqua SA. The small heat shock protein hsp27 is correlated with growth and drug resistance in human breast cancer cell lines. Cancer Res 1993;53:4443-8.

24. Martín B, Aragüés R, Sanz R, Oliva B, Boluda S, Martínez A, et al. Biological pathways contributing to organ-specific phenotype of brain metastatic cells. J Proteome Res 2008;7: 908-20.

25. Ryu JW, Kim HJ, Lee YS, Myong NH, Hwang CH, Lee GS, et al. The proteomics approach to find biomarkers in gastric cancer. J Korean Med Sci 2003;18:505-9.

26. Chen J, Kähne T, Röcken C, Götze T, Yu J, Sung JJ, et al. Proteome analysis of gastric cancer metastasis by two-dimensional gel electrophoresis and matrix assisted laser desorption/ ionization-mass spectrometry for identification of metastasisrelated proteins. J Proteome Res 2004;3:1009-106.

27. Takeno S, Noguchi T, Kikuchi R, Sato T, Uchida Y, Yokoyama $\mathrm{S}$. Analysis of the survival period in resectable stage IV gastric cancer. Ann Surg Oncol 2001;8:215-21.

28. Kapranos N, Kominea A, Konstantinopoulos PA, Savva S, Artelaris S, Vandoros G, et al. Expression of the 27-kDa heat shock protein (HSP27) in gastric carcinomas and adjacent normal, metaplastic, and dysplastic gastric mucosa, and its prognostic significance. J Cancer Res Clin Oncol 2002;128:426-32.

29. Giaginis C, Daskalopoulou SS, Vgenopoulou S, Sfiniadakis I, Kouraklis G, Theocharis SE. Heat shock protein-27, -60 and -90 expression in gastric cancer: association with clinicopatho- logical variables and patient survival. BMC Gastroenterology 2009;9:1-10.

30. Oh TY, Yeo M, Han SU, Cho YK, Kim YB, Chung MH, et al. Synergism of Helicobacter pylori infection and stress on the augmentation of gastric mucosal damage and its prevention with alpha-tocopherol. Free Radic Biol Med 2005;38:1447-57.

31. Nardone G, Rippa E, Martin G, Rocco A, Siciliano RA, Fiengo A, et al. Gastrokine 1 expression in patients with and without Helicobacter pylori infection. Dig Liver Dis 2007;39:122-9.

32. Kim CG, Choi IJ, Lee JY, Cho SJ, Nam BH, Kook MC, et al. Biopsy site for detecting Helicobacter pylori infection in patients with gastric cancer. J Gastroenterol Hepatol 2009;24: 469-74.

33. Marruchella G, Di Leonardo M, Di Guardo G, Romanucci M, Marà M, Tiscar PG, et al. Heat shock proteins (HSPs) 27, 72 and 73 in normal and pre-ulcerative mucosa of the gastric pars oesophagea in swine. J Comp Pathol 2004;131:10-7.

34. Ebert MP, Schäfer C, Chen J, Hoffmann J, Gu P, Kubisch C. Protective role of heat shock protein 27 in gastric mucosal injury. J Pathol 2005;207:177-84.

35. Yeo M, Kim DK, Cho SW, Hong HD. Ginseng, the root of Panax ginseng C.A. Meyer, protects ethanol-induced gastric damages in rat through the induction of cytoprotective heatshock protein 27. Dig Dis Sci 2008;53:606-13.

36. Cornford PA, Dodson AR, Parsons KF, Desmond AD, Woolfenden A, Fordham M, et al. Heat shock protein expression independently predicts clinical outcome in prostate cancer. Cancer Res 2000;60:7099-105.

37. Storm FK, Mahvi DM, Gilchrist KW. HSP-27 has no diagnostic or prognostic significance in prostate or bladder cancers. Adult Urol 1993:42:379-82.

38. Jin HS, Yoshino T, Jin Z, Oka T, Kobayashi K, Yamasaki R, et al. Expression of heat shock protein 60 in normal and neoplastic human lymphoid tissues. J Clin Exp Hematopathol 2002;42:25-32. 